\title{
KARAKTER HABITAT JENIS-JENIS ANGGREK EPIFIT DAN TERESTRIAL DI HUTAN KAMPUNG KANTUMILENA DISTRIK YOKARI KABUPATEN JAYAPURA
}

\author{
(Characters of Epiphyte and Terrestrial Orchids Habitats in Kantumilena Village, \\ Yokari District, Jayapura Regency)
}

\author{
MONIKA DEMENA $^{1}$, EDOWARD KRISSON RAUNSAY ${ }^{2 \varpi}$, VERENA AGUSTINI ${ }^{3}$ \\ Program Pendidikan Biologi, Jurusan Pendidikan Matematika dan Ilmu Pengetahuan Alam, Fakultas Keguruan dan Ilmu \\ Pendidikan Universitas Cenderawasih ${ }^{1,2}$ \\ Program Studi Biologi, Fakultas Matematika dan Ilmu Pengetahuan Alam \\ Universitas Cenderawasih ${ }^{3}$ \\ $\square$ Penulis Korespondensi: Email: edowardraunsay@gmail.com \\ Diterima: 02 Mar 2020| Disetujui: 18 Apr 2020
}

\begin{abstract}
Abstrak. Anggrek dapat tumbuh hampir di semua habitat seperti tanah (terestrial) dan pohon/kayu (epifit). Penelitian ini bertujuan untuk mengidentifikasi jenis-jenis anggrek epifit dan terestrial serta karakter morfologi. Pengumpulan data dilakukan dengan menggunakan metode observasi, survei, dokumentasi dan studi pustaka dan selanjutnya dianalisis secara deskriptif kualitatif. Jenis-jenis anggrek yang terdapat di hutan Kampung Kantumilena merupakan jenis epifit dan terestrial yang terbagi dalam 10 marga dan terdiri dari 20 jenis. Anggrek epifit terdiri dari 16 jenis yaitu Calanthe triplicate (Willemet) Ames, Spathoglottis plicata (Blume), Spathoglottis plicata var alba Blume dan Spathoglotis pulchra Schltr. Sedangkan anggrek terrestrial terdiri dari 16 jenis yaitu Agrostophyllum $\mathrm{sp}^{1}$, Agrostophyllum $\mathrm{sp}^{2}$, Cadetia wariana, Bulbophyllum $\mathrm{sp}^{1}$, Bulbophyllum $\mathrm{sp}^{2}$, Coelogyne $\mathrm{Sp}^{1}$, Coelogyne beccarii (Rchb.f), Dendrobium sp ${ }^{1}$, Dendrobium $\mathrm{sp}^{2}$, Dendrobium $\mathrm{sp}^{3}$, Dendrobium $\mathrm{sp}^{4}$, Dendrobium spectabile (Blume), Dendrobium lineale Rolfe dan Dendrobium controides (T.E.Hunt). Habitat anggrek di lokasi penelitian yaitu pada batang pohon sebagai inang dan tanah.
\end{abstract}

Kata kunci: karakter habitat, jenis anggrek, epifit, terrestrial

Abstract. Orchids can grow in almost all habitats like ground (terrestrial) and trees/wood (epiphytic). This study aimed at identifying types of epiphytic and terrestrial orchids and their morphological characters. The data collection was performed through observation, survey, documentation, and literature review which were then analyzed through descriptive quantitative approach. Types of orchids growing in the forest in Kantumilena Village were epiphytic and terrestrial orchids consisting of 10 clans and 20 types. Epiphyte orchids there had 16 types namely Calanthe triplicate (Willemet) Ames, Spathoglottis plicata (Blume), Spathoglottis plicata var alba Blume and Spathoglotis pulchra Schltr. While terrestrial orchids growing in the site consisted of 16 types including Agrostophyllum sp ${ }^{l}$, Agrostophyllum $s p^{2}$, Cadetia wariana, Bulbophyllum $\mathrm{sp}^{1}$, Bulbophyllum $\mathrm{sp}^{2}$, Coelogyne $\mathrm{Sp}^{1}$, Coelogyne beccarii (Rchb.f), Dendrobium $s p^{1}$, Dendrobium $s p^{2}$, Dendrobium $s p^{3}$, Dendrobium $s^{4}$, Dendrobium spectabile (Blume), Dendrobium lineale Rolfe and Dendrobium controides (T.E.Hunt). The habitats of orchids found in the research site were tree (as host) and ground.

Keywords: characters of habitats, types of orchids, epiphyte, terresterial 


\section{PENDAHULUAN}

Anggrek digolongkan dalam tumbuhan berbiji dari famili Orchidaceae yang memiliki morfologi unik dan memiliki penyebaran di daerah tropis Ikhwal et al. 2019. Anggrek (Orchidaceae) merupakan famili tumbuhan berbunga terbesar dengan jumlah genus mendekati 900 genera dengan perkiraan mendekati $30.000-35.000$ jenis yang tersebar di seluruh dunia (Dressler 1993).

Anggrek dapat tumbuh hampir di semua habitat di dunia kecuali Antartica. Di Indonesia ditemukan sekitar 6000 jenis anggrek dan di Pulau New Guinea dimana Papua merupakan bagian dari New Guinea tumbuh lebih dari 2500 species anggrek. Berdasarkan habitat atau tempat tumbuhnya, maka anggrek dapat dibedakan menjadi epifit, semi epifit, terrestrial dan litofit.

Anggrek tersebut tumbuh dan berkembang di pulau New Guinea meliputi daerah rawa hutan manggore, pantai, dan daratan dengan ketinggian 0 sampai di atas $4000 \mathrm{mdpl}$ (Miller 1978; O'Byrne 1994; Schuitmen and Vogel 2016). Keunikan habitat tersebut membuat anggrek memiliki keanekragaman yang cukup tinggi dan beberapa jenis berdasarkan tempat tumbuh seperti anggrek epifit dan terestrial memiliki populasi yang melimpah.

Keberadaan anggrek epifit di alam sangat bergantung pada komponen hutan sebagai habitatnya yaitu inang atau menempel pada kayu, sehingga anggrek cocok dan hidup pada kondisi lingkungan yang sejuk, kelembaban yang tinggi dan ternaungi dari sinar matahari. Menurut Sutiyoso dan Sarwono (2005) anggrek epifit merupakan anggrek yang menempel inang pohon baik yang masih hidup ataupun mati yaitu pada batang, dahan dan ranting. Memiliki bentuk daun lebar dan relatif tipis, seluruh akarnya yang fungsional menjuntai di udara, sedangkan akar yang menempel pada media (substrat) hanya berfungsi sebagai jangkar, yaitu untuk menahan tanaman pada posisinya.

Sedangkan anggrek terestrial tumbuh liar di alam dan sangat bergantung pada komponen hutan sebagai habitatnya yaitu tanah. Apabila komponen tersebut terganggu, maka dapat mengancam kelestarian dari tanaman anggrek terestrial (Arkadyah dan Lita 2019).

Ekspedisi untuk mengungkap potensi anggrek epifit dan terestrial di Papua belum dilakukan secara komprehensif, mengingat luas wilayah daratan yang luas yaitu 42,08 juta Ha. Penelitian anggrek di Papua dilakukan oleh mahasiswa sebagai kajian dalam menyusun skripsi dan tidak dipublikasikan (Wisnugroho 1998; Wafom 2002). Beberapa penelitian anggrek di Papua yang dipublikasikan dalam jurnal ilmiah baik lokal maupun nasional juga sudah dilakukan oleh beberapa peneliti (Burok dkk. 2009; Agustini dkk. 2012). Keanekaragaman anggrek di Papua yang melimpah dengan wilayah yang sangat luas masih memerlukan penelitian eksplorasi untuk melengkapi data anggrek yang sudah ada.

Kabupaten Jayapura merupakan suatu kabupaten yang terdapat di Papua dengan luas wilayah sekitar $17.515,60 \mathrm{~km}^{2}$. Kawasan hutan yang masih luas, menjadikan kabupaten ini sebagai salah satu sumber penghasil dan habitat anggrek yang layak diperhitungkan (Tanjung dkk. 2012). Penelitian ini dilakukan untuk karakter habitat jenis-jenis anggrek epifit dan terestrial yang terdapat di kampung Kantumilena Distrik Yokari Kabupaten Jayapura.

\section{METODE PENELITIAN}

Penentual lokasi penelitian ini dilaksanakan di hutan Kampung Kantumilena Distrik Yokari Kabupaten Jayapura selama 2 bulan yaitu dari bulan Januari hingga Februari tahun 2017. Populasi dalam penelitian ini adalah semua 
jenis anggrek yang terdapat di hutan Kampung Kantumilena Distrik Yokari Kabupaten Jayapura dan sampelnya adalah semua jenis jenis anggrek yang ditemukan di lokasi penelitian.

\section{Metode Penelitian}

Metode yang digunakan dalam penelitian ini adalah:

1. Metode observasi; observasi dilakukan observasi awal untuk mengumpulkan informasi yang berhubungan dengan topik penelitian.
2. Metode survei; metode ini digunakan dalam pengumpulan data secara eksplorasi (jelajah) di tempat yang menjadi sasaran penelitian.

3. Metode dokumentasi; dokumentasi dilakukan dengan cara pemotretan secara langsung jenis - jenis anggrek yang ditemukan pada lokasi penelitian.

4. Metode studi pustaka; studi pustaka dengan menggunakan berbagai literatur yang berkaitan dengan judul penelitian.
5.

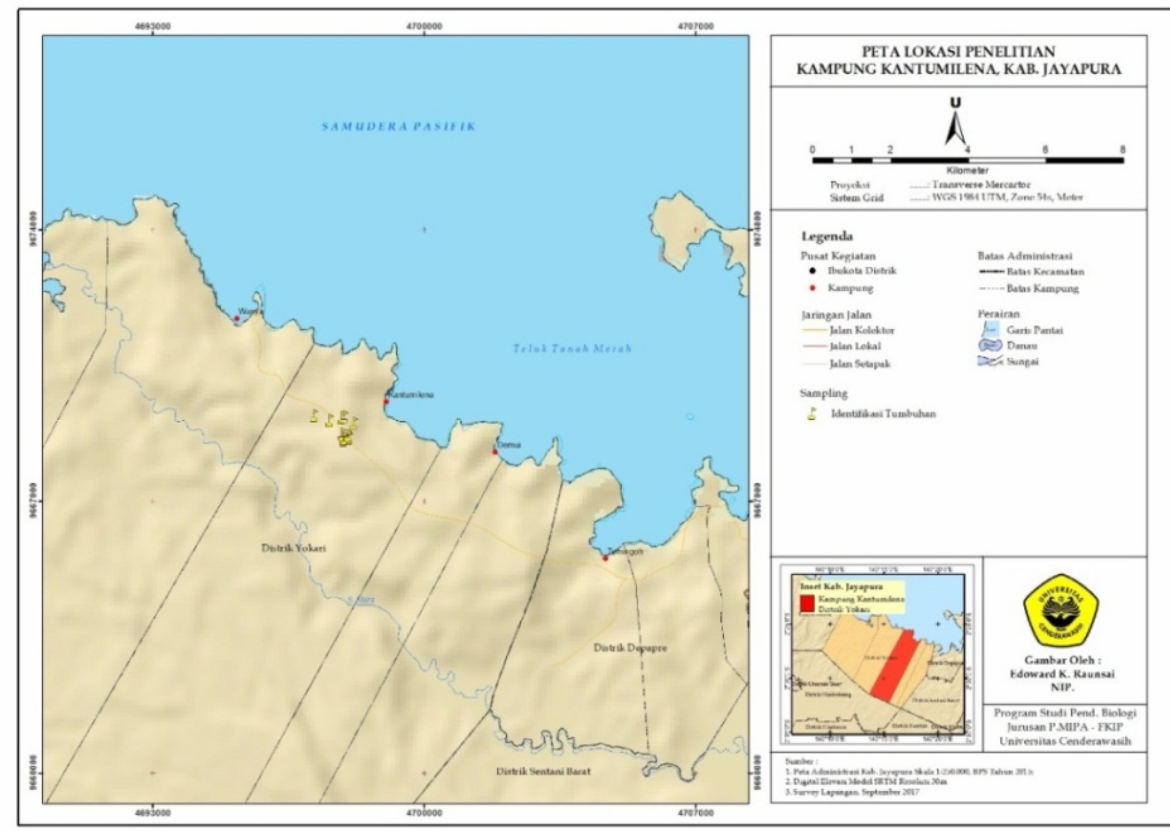

6. Gambar 1. Peta lokasi penelitian

\section{Prosedur Penelitian}

1. Melakukan wawancara secara langsung dengan masyarakat setempat untuk mengetahui lokasi habitat anggrek.

2. Menyiapkan peralatan yang akan digunakan di lapangan.

3. Melakukan Survei ke tempat penelitian untuk memperoleh data tentang karakter habitat anggrek anggrek epifit dan terestrial.

4. Melakukan identifikasi dengan menggunakan buku identifikasi Orchids of
New Guinea, www. ochidsnewguinea com. Orcids Of Borneo: Volume 1.

\section{Analisis Data}

Data yang diperoleh dari hasil pengamatan telah dianalisis secara deskriptif kualitatif yaitu menjelaskan karakter morfologi yang ditemukan antara lain: bentuk, batang, daun, bunga, buah, dan habitat dari anggrek. 


\section{HASIL DAN PEMBAHASAN}

Komposisi Jenis Anggrek

Hutan di Kampung Kantumilena merupakan hutan sekunder habitat tumbuhnya tanaman anggrek. Di hutan Kampung Kantumilena ditemukan beberapa jenis anggrek epifit yang tumbuh pada inangnya, sedangkan anggrek terestrial yaitu anggrek yang ditemukan tumbuh pada tanah. Berdasarkan hasil penelitian, jenisjenis anggrek yang ditemukan pada lokasi penelitian terdiri dari 10 marga, dimana terdapat 16 enggrek epifit dan 4 anggrek terestrial. Marga Calanthe terdiri dari 1 jenis yaitu Calanthe triplicate. Marga Cadetia terdiri dari 1 jenis yaitu Cadetia wariana. Marga Dendrobium terdiri dari 7 jenis yaitu Dendrobium $\mathrm{sp}^{1}$, Dendrobium $\mathrm{sp}^{2}$, Dendrobium $\mathrm{sp}^{3}$, Dendrobium controides (T.E.Hunt), Dendrobium $\mathrm{sp}^{4}$, Dendrobium spectabile (Blume), Dendrobium stratiotes (Rchb.f). Marga Agrostophyllum terdiri dari 2 jenis yaitu, Agrostophyllum $\mathrm{sp}^{1}$ dan Agrostophyllum $\mathrm{sp}^{2}$. Marga Bulbophyllum terdiri dari 2 jenis yaitu Bulbophyllum $\mathrm{sp}^{1}$ dan Bulbophyllum $\mathrm{sp}^{2}$ dan dapat ditunjukkan pada gambar 2. Marga Bulbophyllum hanya ditemukan satu jenis $(B$. obtusipetalum), meskipun marga ini memiliki keanekaragaman jenis terbesar kedua di Borneo berkisar 313 jenis (Vermeulen and O'Byrne 2011; Vermeulen and O'Byrne 2008; Vermeulen and Lamb 2008, Vermeulen 1992; Vermeulen and Anthony 2011).

Keanekaragaman Bulbophyllum untuk Kalimantan telah dilaporkan dari beberapa penelitian, antara lain 27 jenis di Kalimantan Barat (Siregar 2008) dan 15 jenis di Kalimantan Tengah. Keanekaragaman jenis Bulbophyllum pada umunya akan meningkat seiring dengan bertambahnya ketinggian habitat (Vermeulen 1992; Indra dkk. 2016; Dewi dan Widji 2011). Bulbophyllum memiliki keanekaragaman tertinggi pada habitat hutan pegunungan (1000-2500 m dpl) (Vermeulen 1992) sedangkan penelitian ini dilakukan pada ketinggian habitat $300 \mathrm{~m}$ dpl. Marga Coelogyne terdiri dari 2 jenis Coelogyne $\mathrm{sp}^{1}$ dan Coelogyne beccarii (Rchb.f). Marga phreatia terdiri dari 1 jenis yaitu Phreatia micrantha (A.Rich.) Schltr. Marga Vanda terdiri dari 1 jenis yaitu Vanda sp. Marga Spathoglotis terdiri dari 3 jenis yaitu Spthoglottis plicata, Spathoglotis with form, Spatoglotis portus finchii.

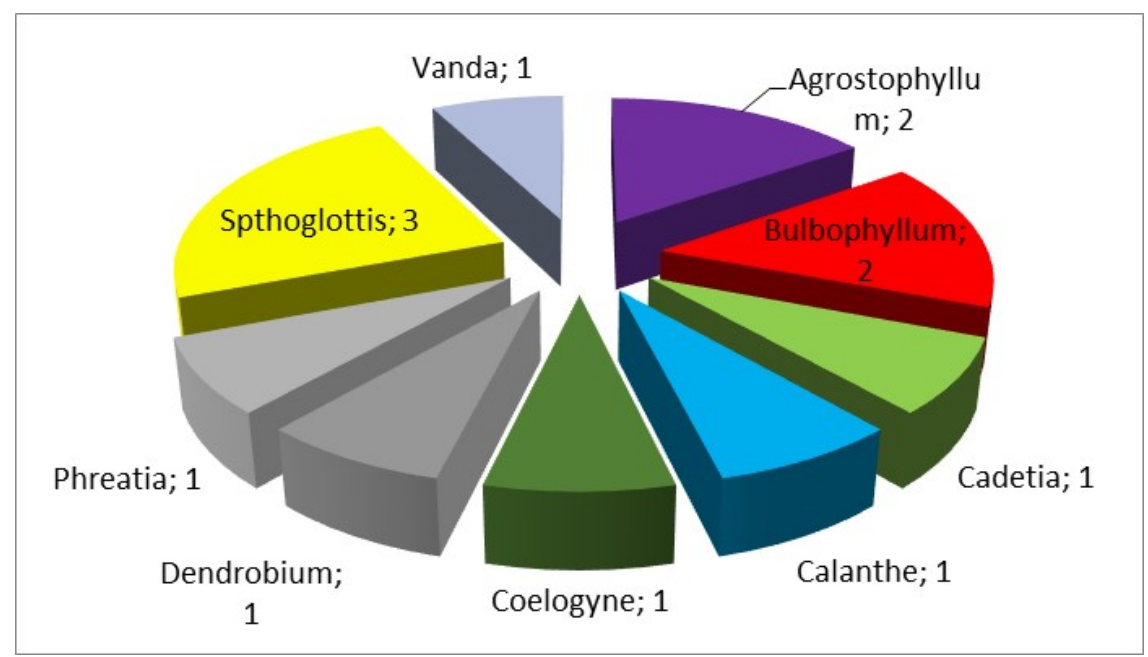

Gambar 2. Jumlah jenis anggrek berdasarkan marga 
Jenis-jenis anggrek yang ditemukan pada lokasi penelitian memiliki habitat yang berbeda yaitu pohon sebagai inang dan tumuh pada tanah. Komposisi jenis anggrek epifit dan terrestrial pada lokasi penelitian menunjukkan bahwa jenis anggrek epifit lebih banyak dibandingkan dengan terrestrial. Anggrek yang tumbuh pada habitat tanah (terrestrial) terdiri dari 4 jenis, sedangkan pada pohon sebagai inang (epifit) terdiri dari 16 jenis dan dapat ditunjukkan pada gambar 3, tabel 1 dan 2.

Komposisi ini memperlihatkan bahwa anggrek epifit lebih dominan dibandingkan dengan terrestrial meskipun hanya ditemukan pada 2 jenis inang yang berebeda. Tingkat kesukaan anggrek epifit pada inang memperlihatkan kesamaan, dimana jenis anggrek tertentu dapat berada pada jenis inang yang berbeda. Jenis anggrek yang memiliki toleransi tinggi dan dapat tumbuh pada inang yang berbeda adalah marga Dendrobium dan Bulbophylum dan dapat ditunjukkan pada gambar 3.

Dendrobium dan Bulbophylum mampu bertoleransi dan tumbuh pada berbagai inang yang berbeda. Hal ini sejalan dengan penelitian Burok dkk. (2009), dimana penelitian ini menemukan beberapa spesies yang termasuk dalam marga Dendromium seperti Dendrobium anthenatum, Dendrobium diskolour Lind, Dendrobium konkolour Lind, Dendrobium johanes. Jenis-jenis ini tumbuh baik pada Sabut Kelapa yang digunakan sebagai inang. Spesies ini merupakan anggrek yang dibudidayakan oleh masyarakat di Distrik Mereuke. Selain itu inang lain seperti kulit kayu Eucalyptus, beberapa spesies Dendrobium seperti Dendrobium anthenatum, Dendrobium diskolour Lind, Dendrobium konkolour Lind, Dendrobium johanes.

Wisnugroho (1998), menemukan hal yang berbeda dimana spesies anggrek yang ditemukan untuk marga Bulbophyllum adalah Bulbophyllum sp. Spesies anggrek ini mampu beradaptasi pada jenis iang yang berbeda seperti Intsia bijuga, Glochidion sp, Aglaia sp, Ficus sp., dan Innocarpus fogiverus. Selain itu jenis anggrek lain yang ditemukan adalah Dendrobium sp. Inang pada spesies ini adalah Zyzygium sp, Glochidion sp, Innocarpus fogiverus, Calophyllum inophyllum, Celtis nerifolia. Jenis anggrek lain ditemukan adalah Dendrobium $\mathrm{sp}^{1}$, dimana inang dari anggrek ini adalah Ficus benjamina, Andenanthera microsperma dan Koordersiodendron pinnatum. Jenis lain yang ditemukan dalam penelitian ini adalah Dendrobium macfarlanei, Dendrobium bifalce dan Dendrobium shculleri. Ketiga Inocarpus fogiverus, Ficus sp, Alstonia sholaris, Aglaia sp, Glochidion sp, dan Terminalia catappa.

Dendrobium dan Bulbophyllum merupakan marga dari beberapa jenis anggrek seperti Dendrobium $\mathrm{sp}, \quad$ Dendrobium $\mathrm{sp}^{1}$, Bulbophyllum lepidum, Bulbophyllum sp, Bulbophyllum $\mathrm{sp}^{1}$. Spesies-spesies ini mampu hidup dan beradaptasi pada inang seperti Tectonia grandis, Cardisopermum halicacabum, Pterocarpus indicu, Casuarina junghuhniana, Avicennia spp, Ficus benjamina, Ficus indica, Ficus septica, Melaleuca leucadendra, Elmerrilla ovalis, Buchanania arborescena, Ficus sp, dan Ficus annulate (Hasanuddin 2010). Sementara Indra dkk. (2016), menemukan anggrek Bulbophyllum lepidum, Bulbophyllum vaginatum, Dendrobium crumenatum, Dendrobium oblongum, Dendrobium smithianum.

Hasil penelitian menunjukkan bahwa faktor lingkungan yang ada di hutan Kantumilena sangat mendukung untuk pertumbuhan anggrek epifit. Hal ini sejalan dengan pernyataan Indra dkk. (2016), bahwa lingkungan dengan inang dan vegetasi yang mendukung akan bermanfaat bagi pertumbuhan anggrek epifit di hutan Bukit Luncit. Tabel 1 menunjukkan bahwa anggrek terestrial di hutan kampung Kantumilena terdiri dari 4 jenis antara lain C. triplicate, S. plicata, 
S. plicata dan S. pulchra. Habitat keempat jenis anggrek tersebut tumbuh pada habitat tanah. Hal ini sejalan dengan pendapat Zulkaidhah dkk. (2018), anggrek yang hidup secara terrestrial atau hidup di tanah disebut sebagai anggrek tanah. Keberadaan keempat anggrek ini pada ketinggian antara 247-503 mdpl dan dapat ditunjukkan pada tabel 1.

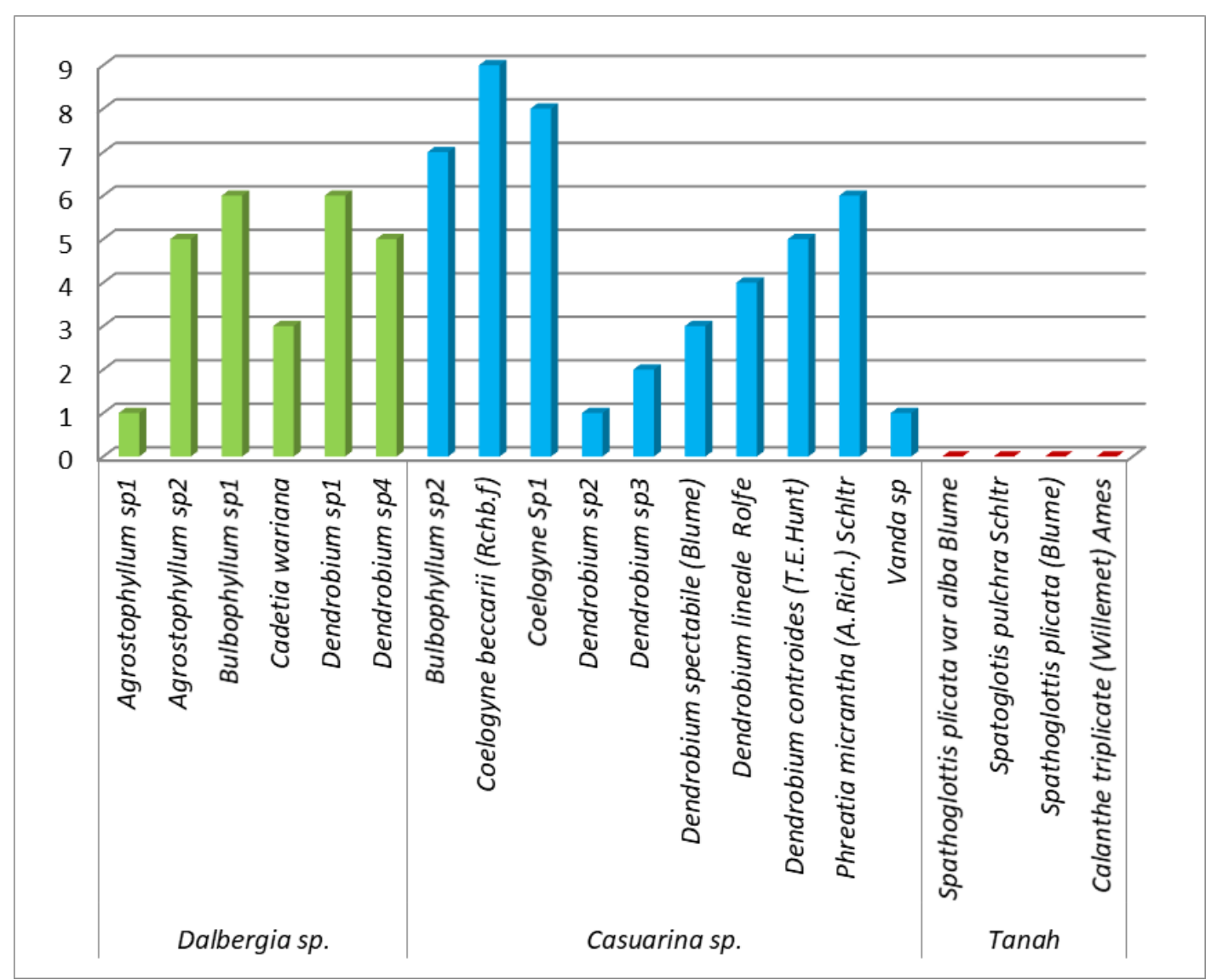

Gambar 3. Grafik ketinggian posisi anggrek pada inang atau habitat

Keberadaan ketinggian anggrek di kampung Kantumilena sejalan dengan hasil penelitian yang dilakukan oleh Gunawan (2007) yang menemukan bahwa anggrek terestrial banyak dijumpai atau ditemukan pada ketinggian $0 \mathrm{~m}-$
$3000 \mathrm{~m}$ dpl. Namun hal bebeda ditunjukkan pada penelitian yang dilakukan oleh Zulkaidhah dkk. (2018), menemukan bahwa anggrek terrestrial dapat ditemukan pada ketinggian 900-1500 mdpl. 
Tabel 1. Jenis-jenis anggrek terestrial

\begin{tabular}{clllc}
\hline No. & \multicolumn{1}{c}{ Marga } & \multicolumn{1}{c}{ Jenis } & Tempat tumbuh & $\begin{array}{c}\text { Ketinggian tempat } \\
\text { (mdpl) }\end{array}$ \\
\hline 1. & Calanthe & Calanthe triplicate (Willemet) Ames & Permukaan tanah & 247 \\
2. & Spathoglottis & Spathoglottis plicata (Blume) & Permukaan tanah & 503 \\
3. & Spathoglottis & Spathoglottis plicata var alba Blume & Permukaan tanah & 503 \\
4. & Spathoglottis & Spathoglotis pulchra Schltr & Permukaan tanah & 503 \\
\hline
\end{tabular}

\begin{tabular}{|c|c|c|c|c|c|c|}
\hline \multirow{2}{*}{$\begin{array}{r}\text { No } \\
1\end{array}$} & \multirow{2}{*}{$\begin{array}{c}\text { Marga } \\
\text { Agrostophyllum }\end{array}$} & \multirow{2}{*}{$\begin{array}{r}\text { Jenis } \\
\text { Agrostophyllum } \mathrm{sp}^{1}\end{array}$} & \multicolumn{2}{|c|}{ Tempat tumbuh/inang } & \multirow{2}{*}{$\begin{array}{l}\text { Tinggi posisi } \\
\text { anggrek (m) } \\
2\end{array}$} & \multirow{2}{*}{$\begin{array}{c}\begin{array}{c}\text { Ketinggian } \\
\text { tempat (mdpl) }\end{array} \\
377\end{array}$} \\
\hline & & & Batang pohon & Dalbergia sp. & & \\
\hline 2 & Agrostophyllum & Agrostophyllum $\mathrm{sp}^{2}$ & Batang pohon & Dalbergia sp. & 2 & 515 \\
\hline 3 & Cadetia & Cadetia wariana & Batang pohon & Dalbergia sp. & 4 & 377 \\
\hline 4 & Bulbophyllum & Bulbophyllum $\mathrm{sp}^{1}$ & Batang pohon & Dalbergia sp. & 2 & 868 \\
\hline 5 & Bulbophyllum & Bulbophyllum $\mathrm{sp}^{2}$ & Batang pohon & Casuarina sp. & 3 & 868 \\
\hline 6 & Coelogyne & Coelogyne $\mathrm{Sp}^{1}$ & Batang pohon & Casuarina sp. & 2 & 714 \\
\hline 7 & Coelogyne & Coelogyne beccarii (Rchb.f) & Batang pohon & Casuarina sp. & 1 & 714 \\
\hline 8 & Dendrobium & Dendrobium $\mathrm{sp}^{1}$ & Batang pohon & Dalbergia sp. & 3 & 377 \\
\hline 9 & Dendrobium & Dendrobium $\mathrm{sp}^{2}$ & Batang pohon & Casuarina sp. & 3 & 512 \\
\hline 10 & Dendrobium & Dendrobium $\mathrm{sp}^{3}$ & Batang pohon & Casuarina sp. & 1 & 714 \\
\hline 11 & Dendrobium & Dendrobium $\mathrm{sp}^{4}$ & Batang pohon & Dalbergia sp. & 3 & 515 \\
\hline 12 & Dendrobium & Dendrobium spectabile (Blume) & Batang pohon & Casuarina sp. & 4 & 350 \\
\hline 13 & Dendrobium & Dendrobium lineale Rolfe & Batang pohon & Casuarina sp. & 4 & 325 \\
\hline 14 & Dendrobium & Dendrobium controides (T.E.Hunt) & Batang pohon & Casuarina sp. & 4 & 540 \\
\hline 15 & Phreatia & Phreatia micrantha (A.Rich.) Schltr & Batang pohon & Casuarina sp. & 1 & 540 \\
\hline 16 & Vanda & Vanda $\mathrm{sp}$ & Batang pohon & Casuarina sp. & 1 & 530 \\
\hline
\end{tabular}


Berdasarkan hasil penelitian memperlihatkan bahwa terdapat 16 jenis anggrek epifit di kampung Kantumilena dan dapat ditunjukkan pada tabel 2. Jenis-jenis anggrek yang tergolong epifit merupakan spesies yang menempel pada berbagai pohon atau inang sebagai habitatnya.

\section{KESIMPULAN}

Berdasarkan hasil penelitian yang dilakukan di hutan Kampung Kantumilena Distrik Yokari Kabupaten Jayapura dapat disimpulkan bahwa jenis-jenis anggrek yang terdapat di hutan Kampung Kantumilena terdiri dari anggrek epifit dan terrestrial dan terbagi dalam 10 marga, dimana terdapat 16 jenis anggrek epifit dan 4 jenis anggrek terestrial.

\section{UCAPAN TERIMA KASIH}

Suksesnya penelitian ini tidak terlepas dari kontribusi semua pihak selama penelitian ini dilaksnakan, untuk itu dengan segala kerendahan hati ingin penulis ucapkan kepada kampung Kantumilila yang telah memberikan ijin kepada penulis sehingga dapat melaksanakan penelitian ini dengan baik. Selain iru terima kasih juga kepada Program Studi Pendidikan Biologi Fakultas Keguruan dan Ilmu Pendidikan yang telah memberikan kesempatan kepada penulis sehingga dapat melaksanakan penelitian ini dengan baik.

\section{DAFTAR PUSTAKA}

Agustini V, Sufaati S, Suharno. 2012. Keragaman jenis anggrek di kawasan hutan distrik Oksibil, Pegunungan Bintang, Papua. Jurnal Biologi Papua. 4(1): 32-37.

Arkadyah DF, Lita S. 2019. Inventarisasi anggrek terestrial di Taman Nasional Bromo Tengger Semeru Blok Ireng-Ireng Kecamatan Senduro Kabupaten Lumajang. Plantropica Jurnal of Agriculktur Science. 158-166.
Burok HG, Tanjung HR, Warpur M. 2009. Domestikasi anggrek di distrik Merauke Kabupaten Merauke Papua. Jurnal Biologi Papua. 1(1): 30-35.

Dewi AL, Widji S. 2011. Inventory and habitat study of orchids species in Lamedai Nature. Biodiversitas. 22-33.

Dressler RL. 1993. Phylogeny and clasification of the orchid family. Published by the Press Syndicate of the University of Cambridge.

Gunawan LW. 2007. Budidaya anggrek. Jakarta: Penebar Swadaya.

Hasanuddin H. 2010. Jenis tumbuhan anggrek epifit di Kawasan Cagar Alam.

Ikhwal RA, Dhafin M, Silda TB, Fadli M, Dzaky IW, Intan, NA. dkk. 2019. Keanekaragaman jenis dan sebaran anggrek di Resort Sukaraja Atas, Taman Nasional Bukit Barisan Selatan, Provinsi Lampung. pp. 153-163.

Indra P, Elvi RP, Riza L. 2016. Jenis-jenis anggrek epifit di hutan Bukit Luncit Kecamatan Anjongan Kabupaten Mempawah. Jurnal Protobiont. 5(3): 1-10.

Millar A. 1978. Orchids of New Guinea. United State of America: Timber Press.

O’Byrne P. 1994. Lowland orchids of Papua New Guinea. SNP Publisher, Pty.Ltd.

Schuitmen A, Vogel D. 2016. Retrieved from www. orchidsnewguinea .com.

Siregar C. 2008. Exploration and inventory of native orchid germplasm in West

Borneo, Indonesia. American Sociaty for Horticultural Science. 43(2): 554-557.

Sutiyoso Y, Sarwono B. 2005. Merawat anggrek. Jakarta: Penebar Swadaya.

Tanjung RH, Suharno, Kalor JD. 2012. Analisis vegetasi dan potensi hutan bukan kayu di kawasan hutan kampung Pagai distrik Airu kabupaten Jayapura Papua. Jurnal Biologi Papua. 4(2): 54-62. 
Vermeulen JJ, O'Byrne P. 2011. Bulbophyllum of Sulawesi. Natural History Publications (Borneo). 7: 247.

Vermeulen JJ, O'Byrne P. 2008. Thirty-two new species of Bulbophyllum (Orchidaceae) from Sulawesi. Gardens' Bulletin Singapore. 60: 73-153.

Vermeulen JJ. 1992. New species of Bulbophyllum, sections Macrouris and Pelma from New Guinea (Orchidaceae). Rheedea. 1-10.

Vermeulen JJ, Anthony L. 2011. Endangered even before formally described: Bulbophyllumkubahensen.sp., a beautiful and assumedly narrowly endemicorchid from Borneo. Plant Syst Evol. 292: 51-53.
Vermeulen JJ, Lamb A. 2008. Fourteen new species of Bulbophyllum from Borneo. Malesian Orchid Journal. 1: 41-70.

Wafom M. 2002. Eksplorasi keragaman anggrek epifit pada pulau-pulau di danau Ayamaru Kabupaten Sorong. [Skripsi]. Universitas Negeri Papua. Manokwari.

Wisnugroho. 1998. Asosiasi antara jenis-jenis anggrek epifit dengan pohon inang pada Kawasan Hutan Wanmori Oransbari Kabupaten Daerah Tingkat II Manokwari. [Skripsi]. Universitas Cenderawasih, Fakultas Pertanian. Manokwari.

Zulkaidhah, Mallombasang SN, Ferdiansah. 2018. Keanekaraagan jenis anggrek alam di desa Lembantongoa kecamatan Palolo kabupaten Sigi. J. ForestSains. 15(2): 58-66. 